\title{
Carpal Pronation and Supination Changes in the Unstable Wrist
}

\author{
Frederick W. Werner, MME ${ }^{1}$ Walter H. Short, MD ${ }^{1}$ \\ ${ }^{1}$ Department of Orthopedic Surgery, SUNY Upstate Medical \\ University, Syracuse, New York
}

Address for correspondence Frederick W. Werner, MME, Department of Orthopedic Surgery, SUNY Upstate Medical University, 750 East

J Wrist Surg 2018;7:298-302. Adams Street, Syracuse, NY 13210 (e-mail: wernerf@upstate.edu).

\begin{abstract}
Keywords

- scapholunate dissociation

- scaphoid

- lunate

Background Little is known about changes in scaphoid and lunate supination and pronation following scapholunate interosseous ligament (SLIL) injury. Information on these changes may help explain why some SLIL reconstructions have failed and help in the development of new techniques.

Purpose To determine if following simulated SLIL injury there was an increase in scaphoid pronation and lunate supination and to determine if concurrently there was an increase in the extensor carpi ulnaris (ECU) force.

Materials and Methods Scaphoid and lunate motion were measured before and after sectioning of the SLIL and two volar ligaments in 22 cadaver wrists, and before and after sectioning of the SLIL and two dorsal ligaments in 15 additional wrists. Each wrist was dynamically moved through wrist flexion/extension, radioulnar deviation, and a dartthrowing motion. Changes in the ECU force were recorded during each wrist motion. Results Scaphoid pronation and lunate supination significantly increased following ligamentous sectioning during each motion. There were significant differences in the amount of change in lunate motion, but not in scaphoid motion, between the two groups of sectioned ligaments. Greater percentage ECU force was required following ligamentous sectioning to achieve the same wrist motions.

Conclusion Carpal supination/pronation changed with simulated damage to the scapholunate stabilizers. This may be associated with the required increases in the ECU force.

Clinical Relevance In reconstructing the SLIL, one should be aware of the possible need to correct scaphoid pronation and lunate supination that occur following injury. This may be more of a concern when the dorsal stabilizers are injured.
\end{abstract}

Scapholunate dissociation can occur after a fall on an outstretched hand and is seen as gapping between the scaphoid and lunate and as changes in their angular alignment in the sagittal plane. ${ }^{1}$ Surgical reconstruction of the torn scapholunate interosseous ligament (SLIL) is performed to reduce the gap and restore the normal alignment of the bones. ${ }^{1}$ Several studies have shown that scaphoid pronation (-Fig. 1) occurs following SLIL tears. ${ }^{2,3}$ SalvaColl et $\mathrm{al}^{3}$ identified the extensor carpi ulnaris (ECU)

received

October 25, 2017

accepted after revision

March 17, 2018

published online

April 24, 2018 muscle as causing scaphoid pronation especially in wrists with scapholunate advanced collapse (SLAC). Based on their study using static tendon loading, the authors suggested that in the presence of SLAC, one should avoid ECU muscle contraction.

Several studies ${ }^{4-6}$ have examined changes in scaphoid flexion/extension and radioulnar deviation during wrist motion following simulated SLIL tears. Less is known about scaphoid and lunate supination and pronation. Information

Copyright $\odot 2018$ by Thieme Medical Publishers, Inc., 333 Seventh Avenue, New York, NY 10001, USA.

DOI https://doi.org/ 10.1055/s-0038-1642615. ISSN 2163-3916. 




Fig. 1 Transverse and volar views of the scaphoid, lunate, distal radius, and ulna, with the wrist in a neutral flexion/extension and neutral radioulnar deviation position. The left column of images shows the position of the scaphoid and lunate with all ligaments intact, the middle column following sectioning of the scapholunate interosseous ligament, radioscaphocapitate ligament, and scaphotrapezial ligament, and the right column after 1,000 cycles of wrist motion following ligament sectioning. These models do not include cartilage; therefore, when the ligaments are intact, a slight gap between the subchondral bone surfaces is visible. In this illustrative arm, after 1,000 cycles of motion, the scaphoid pronates. The direction of lunate supination is shown to illustrate this direction. (Adapted with permission from Short et al. ${ }^{5}$ )

about these changes may explain why some reconstructions have failed and lead to the development of new techniques.

The purpose of this study was to (1) compare changes in scaphoid pronation and lunate supination during dynamic wrist motions after different groups of ligamentous stabilizers between the scaphoid and lunate were sectioned and (2) determine whether the ECU tendon force is greater following SLIL sectioning. Our hypotheses were that following ligamentous sectioning, greater ECU forces would be required to achieve the same wrist motions and that scaphoid pronation and lunate supination would be greater following SLIL sectioning.

\section{Materials and Methods}

Data from 37 fresh cadaver wrists (average 68 years, 20 males, 17 females) previously tested in a computer-controlled wrist joint motion simulator were analyzed. In the original studies, ${ }^{4-6}$ a sample size of eight wrists had been determined to have sufficient power to detect changes in scaphoid and lunate motion when different stabilizing ligaments were sectioned in different sequences.

Each wrist was prepared by identifying five wrist tendons (ECU, extensor carpi radialis brevis, extensor carpi radialis longus, flexor carpi radialis, and flexor carpi ulnaris). By pulling on these tendons with individual servo actuators, each wrist was cyclically moved through a flexion/extension motion, a radioulnar deviation motion, and a dart-throwing motion., ${ }^{4,7}$

Electromagnetic motion sensors were attached to the scaphoid, lunate, and third metacarpal so that the motion of each bone was recorded during each wrist motion relative to a fourth sensor attached to the distal radius. The accuracy of these sensors in this setting was previously reported to be 0.2 degrees and $0.2 \mathrm{~mm} .{ }^{8}$ Data were acquired with the wrist intact in all 37 wrists and then in 22 after 1,000 cycles of repetitive motion following sectioning of the SLIL and two volar ligaments, the scaphotrapezial ligament (STT) and the radioscaphocapitate ligament (RSC). In the remaining 15 wrists, data were collected after sectioning three ligaments; the dorsal intercarpal ligament (DIC), the dorsal radiocarpal ligament (DRC), and the SLIL, followed by 1000 cycles of motion.

The SLIL was sectioned midway between the scaphoid and lunate and included all three sections of the ligament. The STT and RSC ligaments were sectioned halfway between their origin and insertion. The DRC was sectioned at its origin on the radius. The DIC was sectioned as the DIC traversed between the scaphoid and capitate. During each motion, the tendon forces required to achieve each motion were also measured. During the fourth cycle of each motion, at every $12 \mathrm{~ms}$, the percent ratio of the ECU force to the sum of all tendon forces was determined. The average ratio over the cycle and the ratio at the maximums at each extreme of motion were determined. Similarly, for each motion, the amount of scaphoid and lunate pronation relative to the third metacarpal pronation/supination angle was determined. Changes in carpal motion were computed on average over the fourth cycle of wrist motion, the largest change, and the change at specific extremes of wrist motion.

A mixed-mode two-way analysis of variance was used to compare differences in the collected data between the intact wrist and after ligamentous sectioning and between the two groups of sectioned ligaments. 


\section{Results}

Scaphoid pronation significantly increased with ligamentous sectioning during each wrist motion. During the wrist flexion/extension motion (-Table 1) and the dart-throwing motion (-Table 2), there were significant increases $(p<0.004)$ in all of the cases shown in each table (at the extremes of wrist motion, for the average over the wrist motion, and for the largest increase during the motion compared with before sectioning). During the radioulnar deviation motion, there were significant increases $(p<0.019)$ for all cases shown in - Table 3, except at maximum ulnar deviation ( $p=0.63$ ).

There was also a significant increase in lunate supination with ligamentous sectioning at maximum wrist extension $(p=0.015)$ and for the largest increase during the motion

Table 1 Average increase in scaphoid pronation and lunate supination after ligamentous sectioning (degree) during the wrist flexion/extension motion

\begin{tabular}{|l|l|l|l|l|}
\hline & $\begin{array}{l}\text { Average over cycle } \\
\text { of motion }\end{array}$ & $\begin{array}{l}\text { At max wrist } \\
\text { flexion }\end{array}$ & $\begin{array}{l}\text { At max wrist } \\
\text { extension }\end{array}$ & $\begin{array}{l}\text { Largest increase } \\
\text { during motion }\end{array}$ \\
\hline $\begin{array}{l}\text { Scaphoid pronation after SLIL and } \\
\text { volar ligaments cut }\end{array}$ & $3.5(4.7)$ & $3.1(3.4)$ & $3.1(6.5)$ & $7(4.3)$ \\
\hline $\begin{array}{l}\text { Scaphoid pronation after SLIL and } \\
\text { dorsal ligaments cut }\end{array}$ & $2.9(2.7)$ & $2.3(3.5)$ & $2.4(2)$ & $6.2(3.2)$ \\
\hline $\begin{array}{l}\text { Lunate supination after SLIL and } \\
\text { volar ligaments cut }\end{array}$ & $-0.2(2.3)$ & $-2.7(3)$ & $0.2(2.3)$ & $3.1(3.9)$ \\
\hline $\begin{array}{l}\text { Lunate supination after SLIL and } \\
\text { dorsal ligaments cut }\end{array}$ & $2.7(2.3)$ & $2.7(2.9)$ & $1.8(2.4)$ & $5.6(3.2)$ \\
\hline
\end{tabular}

Abbreviation: SLIL, scapholunate interosseous ligament.

Note: Standard deviation is given in parentheses.

Table 2 Average increase in scaphoid pronation and lunate supination after ligamentous sectioning (degree) during the dartthrowing motion

\begin{tabular}{|l|l|l|l|l|}
\hline & $\begin{array}{l}\text { Average over cycle } \\
\text { of motion }\end{array}$ & $\begin{array}{l}\text { At max wrist } \\
\text { flexion }\end{array}$ & $\begin{array}{l}\text { At max wrist } \\
\text { extension }\end{array}$ & $\begin{array}{l}\text { Largest increase } \\
\text { during motion }\end{array}$ \\
\hline $\begin{array}{l}\text { Scaphoid pronation after SLIL and } \\
\text { volar ligaments cut }\end{array}$ & $2.8(4.7)$ & $2.2(3.9)$ & $3.2(5.2)$ & $6.1(3.9)$ \\
\hline $\begin{array}{l}\text { Scaphoid pronation after SLIL and } \\
\text { dorsal ligaments cut }\end{array}$ & $2.9(2.1)$ & $3.6(2.9)$ & $1.7(1.2)$ & $5.3(3)$ \\
\hline $\begin{array}{l}\text { Lunate supination after SLIL and } \\
\text { volar ligaments cut }\end{array}$ & $0.3(2.2)$ & $-0.6(2.1)$ & $0.5(2.3)$ & $2.5(3.3)$ \\
\hline $\begin{array}{l}\text { Lunate supination after SLIL and } \\
\text { dorsal ligaments cut }\end{array}$ & $2.2(2.4)$ & $1.7(2.5)$ & $1.8(2.7)$ & $4(2.7)$ \\
\hline
\end{tabular}

Abbreviation: SLIL, scapholunate interosseous ligament.

Note: Standard deviation is given in parentheses.

Table 3 Average increase in scaphoid pronation and lunate supination after ligamentous sectioning (degree) during the wrist radioulnar deviation motion

\begin{tabular}{|l|l|l|l|l|}
\hline & $\begin{array}{l}\text { Average over cycle } \\
\text { of motion }\end{array}$ & $\begin{array}{l}\text { At max wrist radial } \\
\text { deviation }\end{array}$ & $\begin{array}{l}\text { At max wrist ulnar } \\
\text { deviation }\end{array}$ & $\begin{array}{l}\text { Largest increase } \\
\text { during motion }\end{array}$ \\
\hline $\begin{array}{l}\text { Scaphoid pronation after SLIL and } \\
\text { volar ligaments cut }\end{array}$ & $1.8(5.9)$ & $5.1(6)$ & $-2(6.3)$ & $6.5(4.7)$ \\
\hline $\begin{array}{l}\text { Scaphoid pronation after SLIL and } \\
\text { dorsal ligaments cut }\end{array}$ & $2.2(3)$ & $2.1(2.4)$ & $1.1(4.8)$ & $4.8(3.2)$ \\
\hline $\begin{array}{l}\text { Lunate supination after SLIL and } \\
\text { volar ligaments cut }\end{array}$ & $0.3(2.2)$ & $1(2.9)$ & $-0.6(2.7)$ & $2.2(2.7)$ \\
\hline $\begin{array}{l}\text { Lunate supination after SLIL and } \\
\text { dorsal ligaments cut }\end{array}$ & $2.5(2.9)$ & $2.8(3.4)$ & $1.5(2.6)$ & $4(3.1)$ \\
\hline
\end{tabular}

Abbreviation: SLIL, scapholunate interosseous ligament.

Note: Standard deviation is given in parentheses. 
$(p=0.001)$ during the wrist flexion/extension motion (-Table 1). There were also significant increases for all cases shown in - Table 3 during the radioulnar deviation motion ( $p<0.002$, except at maximum ulnar deviation). During the dart-throwing motion (-Table 2 ), there were again significant increases in lunate supination $(p<0.009$, except at maximum flexion).

There was no significant difference in the increase of scaphoid pronation between the two groups of sectioned ligaments in any of the cases in - Tables 1, 2, or $\mathbf{3}$ during the wrist flexion/extension motion $(p>0.52)$, during the radioulnar deviation motion $(p>0.08)$, and during the dartthrowing motion $(p>0.28)$. However, there was a significant difference in the amount of lunate supination between the two groups of sectioned ligaments during the wrist flexion/extension motion at maximum wrist flexion $(p=0.001)$, at maximum wrist extension $(p=0.048)$, and for the average over the wrist motion $(p=0.001)$. There was a significant difference between the two groups of ligaments during the wrist radioulnar deviation motion for the average over the wrist motion ( $p=0.012)$ and at maximum ulnar deviation $(p=0.021)$. There was also a significant difference between the two groups of ligaments during the dartthrowing motion for the average over the wrist motion $(p=0.019)$ and at maximum extension $(p=0.005)$.

Greater percentage ECU forces were required with ligamentous sectioning to achieve the same wrist motions (-Table 4, $p<0.013$ for all three wrist motions). No significant differences were observed between the two sectioned groups of ligaments $(p>0.30)$.

\section{Discussion}

The primary purpose of this study was to determine whether scaphoid pronation and lunate supination increased following simulated injury to various scapholunate stabilizers. Our results demonstrate that there is increased scaphoid pronation and lunate supination during each of the tested wrist motions for most of the parameters considered (average, maximum, and at the end points of motion). The second purpose of this study was to determine whether the ECU tendon force needs to be greater to achieve the same motions as before ligamentous sectioning. This was also shown to occur.
One limitation of this study is that the results are based on sectioning ligaments to simulate injury and in the absence of any healing that would occur in vivo. However, each arm served as its own control, which strengthens the findings.

In this study, we found that the scaphoid pronated and the lunate supinated with sectioning of the SLIL and secondary stabilizing structures. Short et $\mathrm{al}^{2}$ also found the scaphoid pronated with SLIL sectioning but did not see a change in lunate supination/pronation, perhaps due to them not sectioning any secondary ligaments. In this study, the changes in lunate supination were significantly related to which set of secondary ligaments was sectioned. This may imply that there are different types of SLIL instabilities.

Greater ECU tendon forces were required after ligamentous sectioning to cause the wrist to go through the same dynamic wrist motions. Salva-Coll et $\mathrm{al}^{3}$ identified the ECU muscle as causing scaphoid pronation especially in wrists with SLAC. In our study, there appears to be an association between increased ECU force and scaphoid pronation, but it is unclear which is the cause and which is the effect.

It is the authors' opinion that the cause for the increase in scaphoid pronation and lunate supination is decreased ligamentous restraints and the indirect forces on these carpal bones from the forces applied to the wrist tendons. It may be that after ligament sectioning, the scaphoid and lunate motion is more under the control of the bony geometry. ${ }^{9}$ In the intact specimen, ligamentous restraints control carpal bone position. It is our conclusion that after ligament sectioning, there is a change in position of the scaphoid and lunate, which necessitates altering the forces on the wrist tendons to maintain the same wrist motion. The data also suggest that there may be several variations of scapholunate instability, depending upon which ligaments are sectioned.

These results that show the forces causing the scaphoid to pronate and pull away from the lunate may provide a reason why some methods used to repair or reconstruct the dorsal SLIL have had limited success. When performing a surgical repair or reconstruction to reduce the scaphoid and lunate, one might want to consider that the scaphoid may have pronated following injury. This type of separation may be a greater problem following injury to the dorsal stabilizers.

Table 4 Average increase in the ECU force as percent of all tendon forces after ligamentous sectioning during the three wrist motions

\begin{tabular}{|l|l|l|l|}
\hline & $\begin{array}{l}\text { During wrist flexion/ } \\
\text { extension motion }\end{array}$ & $\begin{array}{l}\text { During wrist radioulnar } \\
\text { deviation motion }\end{array}$ & $\begin{array}{l}\text { During wrist dart-throwing } \\
\text { motion }\end{array}$ \\
\cline { 2 - 4 } & At max wrist extension & $\begin{array}{l}\text { At max wrist ulnar } \\
\text { deviation }\end{array}$ & $\begin{array}{l}\text { At max flexion and ulnar } \\
\text { deviation }\end{array}$ \\
\hline With SLIL and volar ligaments cut & $5.6(11.1)$ & $10.5(11.4)$ & $7.4(9.6)$ \\
\hline With SLIL and dorsal ligaments cut & $2.4(5.9)$ & $10.6(9.9)$ & $12.5(8.5)$ \\
\hline
\end{tabular}

Abbreviations: ECU, extensor carpi ulnaris; SLIL, scapholunate interosseous ligament.

Note: Standard deviation is given in parentheses. 


\section{Ethical Approval}

As this was a cadaver study, no institutional review board approval was required.

\section{Funding}

This study was funded, in part, by the Department of Orthopedic Surgery, SUNY Upstate Medical University, Syracuse, New York. This study was also funded by National Institute of Arthritis and Musculoskeletal and Skin Diseases grant 1R01 AR050099.

\section{Conflict of Interest}

None.

\section{References}

1 Kitay A, Wolfe SW. Scapholunate instability: current concepts in diagnosis and management.J Hand Surg Am 2012;37(10):2175-2196

2 Short WH, Werner FW, Fortino MD, Palmer AK, Mann KA. A dynamic biomechanical study of scapholunate ligament sectioning. J Hand Surg Am 1995;20(06):986-999
3 Salva-Coll G, Lluch-Bergada A, Garcia-Elias M, Espugas-Mimo M, Llusa-Perez M. Kinetics of the wrist in scapholunate advanced collapse. Hand (NY) 2016;11:12S-13S

4 Short WH, Werner FW, Green JK, Masaoka S. Biomechanical evaluation of ligamentous stabilizers of the scaphoid and lunate. J Hand Surg Am 2002;27(06):991-1002

5 Short WH, Werner FW, Green JK, Masaoka S. Biomechanical evaluation of the ligamentous stabilizers of the scaphoid and lunate: part II. J Hand Surg Am 2005;30(01):24-34

6 Short WH, Werner FW, Green JK, Sutton LG, Brutus JP. Biomechanical evaluation of the ligamentous stabilizers of the scaphoid and lunate: part III. J Hand Surg Am 2007;32(03): 297-309

7 Werner FW, Palmer AK, Somerset JH, et al. Wrist joint motion simulator. J Orthop Res 1996;14(04):639-646

8 Short WH, Werner FW, Green JK, Weiner MM, Masaoka S. The effect of sectioning the dorsal radiocarpal ligament and insertion of a pressure sensor into the radiocarpal joint on scaphoid and lunate kinematics. J Hand Surg Am 2002;27(01): 68-76

9 Werner FW, Short WH, Green JK, Evans PJ, Walker JA. Severity of scapholunate instability is related to joint anatomy and congruency. J Hand Surg Am 2007;32(01):55-60 